\title{
Erratum: Views of schizophrenia patients on the effects of cannabis on their mental health
}

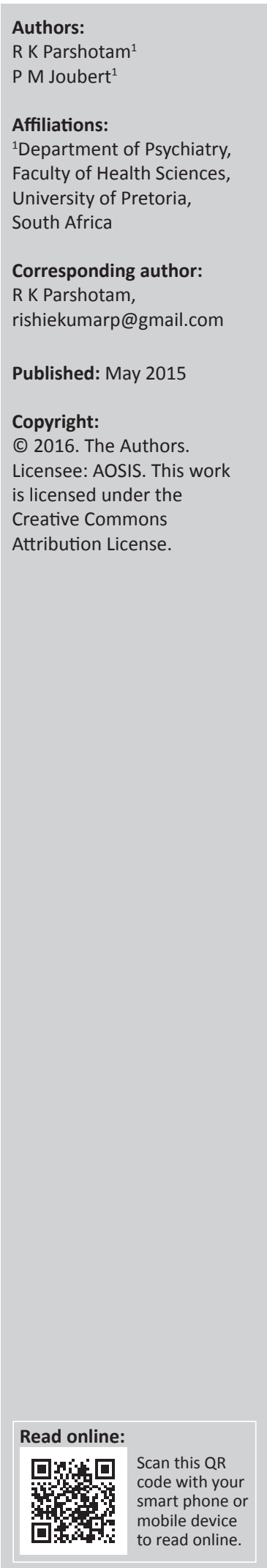

\section{Authors:}

Rarshotam

Affiliations:

${ }^{1}$ Department of Psychiatry, Faculty of Health Sciences, University of Pretoria, South Africa

\section{R K Parshotam,}

\section{Copyright:}

(C) 2016. The Authors.

OSIS. This wor
This article was erroneously published in 2015 under the DOI citation S Afr J Psychiatr 2015;22(2) instead of the correct S Afr J Psychiatr 2015;21(2). 